


\title{
O OCIDENTE COMO PROBLEMA FILOSÓFICO
}

\author{
Laurenio Leite Sombra'
}

RESUMO: Este artigo visa refletir sobre a prática de Filosofia na América Latina a partir da relação deste continente com a ideia de "Ocidente". Para tanto, empreende uma reflexão filosófica sobre esta ideia, assim como sobre noções a ela correlacionadas, como modernidade e colonialidade. Apresenta, nesta perspectiva, a noção de "paradoxo da modernidade", pelo poder que a modernidade tem de incluirexcluir sujeitos e valores. Ao pensar a filosofia na América Latina, reflete sobre a própria natureza do conceito de filosofia e as implicações dessa noção em relação a um pensar situado (ou à ausência desse pensar) na América Latina.

PALAVRAS-CHAVE: Ocidente; Modernidade; Colonialidade; Filosofia; América Latina.

ABSTRACT: This article aims to reflect on the practice of Philosophy in Latin America in terms of the relationship between this region and the idea of "the West". To do so, it undertakes a philosophical reflection on this idea, as well as on notions correlated to it, such as modernity and coloniality. From this perspective, it examines the notion of "paradox of modernity", related to the power of modernity to includeexclude subjects and values. In thinking about philosophy in 
Latin America, it reflects on the very nature of the concept of philosophy, and the implications of this notion in relation to a situated thought (or the absence of such thinking) in Latin America.

KEYWORDS: West; Modernity; Coloniality; Philosophy; Latin America. 
Num site conservador norte-americano coordenado pelo falecido ensaísta Lawrence Auster, foi levantada a questão: seriam os hispânicos ocidentais? Outro norte-americano conservador, o advogado Howard Shuterland, responde categoricamente, ele que teria conhecido bem o México e morado lá por um tempo: certamente poderíamos considerar como ocidentais Borges, Villa-Lobos ou Octavio Paz. Mas o mesmo não se pode dizer das "dezenas de milhões de mestiços e indígenas que invadem os Estados Unidos". E vai mais além:

Eles são descendentes dos escravos indígenas précolombianos, não da Espanha ou de qualquer parte da Europa. Sua cristandade (frequentemente só de nome, para começar) é um verniz sobre uma antiga e, francamente, sombria herança indígena (são seus críticos familiarizados com os costumes religiosos e sociais das culturas pré-colombianas?) $)^{2}$

Em seguida, ele sugere que o mesmo vale para os africanos. Esta característica, que ele viu mais de perto no México, suspeita que seja equivalente em todo país latino-americano - "exceto, talvez, Argentina, Uruguai e - em alguma medida - o Chile". E é "totalmente diferente de Estados Unidos, Canadá, Austrália e Nova Zelândia”. Na América Latina, em geral, há uma maioria da população nativa "dominada em cada caso por oligarquias brancas que raramente se misturam com os meios mestiços e indígenas e nunca tentaram tornálos ocidentais".

O site, onde discussões como estas eram recorrentes, frequentemente discutia a "questão ocidental" em correlação 
com o tema da imigração, especialmente dos imigrantes que chegam aos Estados Unidos, os "hispânicos" que, ainda segundo os termos de Shuterland, estão “inundando a América!". Tal manifestação, que está muito longe de ser isolada, me interessa aqui particularmente por algumas razões. Em primeiro lugar ela ressalta, em tintas fortes, uma noção mais ou menos explícita da noção de "Ocidente": ela sempre pressupõe, em sua formulação, algo que seja "não ocidental", cuja relação com o Ocidente pode se dar de diversas formas: desde um confronto cada vez mais direto (HUNTINGTON, 1993), passando por relações de domínio, mas também de exclusão, como a tentativa de evitar a "inundação de imigrantes". Nesse sentido, mais do que uma definição teórica, a ideia de Ocidente (e seu oposto) pressupõe diversas e frequentemente tensas práticas de relações humanas. Em segundo lugar, as afirmações de Shuterland trazem a incômoda e ambígua presença da América Latina nesse cenário. A ambiguidade de sua formação entre "oligarquias brancas" e "povos mestiços" a coloca numa espécie de entreposto entre mundo ocidental e não ocidental. É ela que faz Huntington pensar a América Latina como uma das diferentes "civilizações" do planeta, mas, assim como o Leste europeu, com maior proximidade cultural do "Ocidente", o que faz com que elas devam ser "incorporadas às sociedades ocidentais" (HUNTINGTON, 1993, p. 19).

Nesse universo latino-americano, naturalmente se faz filosofia e se produzem reflexões, que podemos considerar filosóficas $^{3}$. E esse exercício se fez primordialmente, de forma acadêmica ou não, a partir da influência de produções intelectuais de países que ocupam o centro da reflexão 
ocidental: Alemanha, França, Inglaterra e, mais recentemente, Estados Unidos, com uma ou outra produção importante da Itália ou da Espanha. Eventualmente, autores de outros países ganharam relevância, mas normalmente inseridos nesse universo e escrevendo nessas línguas. Estes países hegemônicos também intermediaram produções mais antigas, como o pensamento medieval e romano (em língua latina) e o pensamento grego clássico.

Se a produção filosófica hegemônica da América Latina seguiu, em geral, esse cânone, certamente, houve e há reações a ele. Nos anos 70, o movimento da filosofia da libertação, comandado por filósofos como Enrique Dussel, Carlos Cullen, Rodolfo Kusch e Juan Carlos Scannone, foi fundamental para repensar uma possibilidade particular de reflexão filosófica a partir da América Latina (ARDILES Et al, 1973). Nos anos 90, foi formado o projeto multidisciplinar "modernidade/ colonialidade", com diversos intelectuais latino-americanos, que voltavam a resgatar aportes da filosofia da libertação, especialmente a releitura de Dussel sobre a modernidade, mas incluía conceitos como o de colonialidade do poder, de Aníbal Quijano; sistema-mundo, de Immanuel Wallerstein; e os integrava a teorias pós-colonialistas, pós-estruturalistas e feministas, entre outras (LANDER (Comp.), 1993; CASTRO-GÓMES e GROSFOGUEL (Ed.), 2007), numa ampla discussão que tem repensado a própria noção de modernidade, a articulando de modo indissociável com a ideia de colonialidade. A partir do Brasil, o filósofo Julio Cabrera tem comandado há alguns anos uma reflexão poderosa sobre a prática filosófica no Brasil e na América Latina (CABRERA, 2013). Certamente, este artigo é devedor do diálogo com esses autores. 
A questão que se coloca aqui é: em que medida pensar a questão do Ocidente torna-se um problema fundamental para pensar a nossa prática filosófica, especialmente na América Latina? Empreender essa reflexão significa pensar, mais uma vez, a que corresponde esta ideia de Ocidente, de um lado, e o que significa a prática filosófica circunstanciada (no caso, na América Latina), de outro. Ambos os procedimentos desenvolvidos a partir de perspectiva que tenho já tentado formular anteriormente.

\section{REDE DE SENTIDOS COMO UM “MÉTODO” DE INVESTIGAÇÃO}

Em algumas publicações anteriores (SOMBRA, 2015a e 2015b) tenho formulado uma perspectiva, que considero simultaneamente hermenêutica e política, de que o nosso modo de agir e significar o mundo é sempre antecedido por uma configuração profunda, não totalmente consciente e explicitável, a que chamei de rede de sentidos. Esta configuração é histórica, e como tal transformável no decorrer do tempo, e é constituída "performativamente" a partir de diversos rituais diários de conformação do nosso modo de agir, sentir e significar o mundo.

Considerando-se que somos "animais linguísticos", a rede de sentidos conforma uma ambiência prévia que é profundamente valorativa, hierarquizando de modo complexo alguns dos signos fundamentais que compõem nosso modo de vida: atributos como coragem, força física, inteligência, honestidade, bondade, ousadia, controle das emoções, sabedoria, esperteza (e seus opostos); identidades de sujeitos 
como homem, branco, rico, ocidental, cristão, heterossexual, entre outros (e seus contrários); figuras históricas, deuses e mesmo percepções estéticas concernentes ao que nos atrai e o que nos provoca repulsa. Todos esses signos, mas acima de tudo a prática e o nosso modo cotidiano de lidar com eles, compõem essa ampla cadeia valorativa que nos conforma. Mas não de uma forma totalmente explicitável ou racional. Se todo signo carrega em si, pela sua permanência no tempo, uma promessa de identidade, o seu exercício prático e singular traz, em maior ou menor medida, a marca da diferença, condição que dificulta, em última instância, as definições precisas. Nesse contexto, o mais importante não é o que dizemos ser valioso em nossas vidas, mas que valorizações nosso modo de vida e nossas preferências denunciam.

Nesse contexto, é a prática que propicia uma totalidade, ainda que precária, à nossa produção de sentidos. É ela que permite que sejamos capazes, também precariamente, de articular os diversos signos que compõem a nossa rede e compreendê-los, de forma relacionada. Se Saussure (2012) e toda uma geração de pensadores que o sucedeu já percebia que os signos só podem ser compreendidos em relação mútua, é o emaranhado dessa relação que é capaz de formar uma ampla rede. Entretanto, a sua semântica não é capaz de "falar por si”. Como afirma Wittgenstein $(2005,426)$, só o uso/costume [Gebrauch] é capaz de dar vida a um signo, a semântica precisa ser acompanhada de uma pragmática, por mais imprecisa e até parcialmente incoerente que ela seja.

Vale citar, também, que toda rede de sentidos carrega em si uma (ou várias) temporalidade(s), pensada(s) em diálogo com o sentido dado por Heidegger (2009) ao termo. Ou seja: 
nosso modo de dar sentido e agir no mundo é articulado por certa perspectiva de passado articulada com certa expectativa de futuro. Estes aspectos estão profundamente imbricados, e transformam-se mutuamente. Ambos, ademais, são aspectos valorativos: não representam visões neutras sobre passado e futuro, mas modos significativos de articulá-los com a visão do presente, com a ambiência com a qual se dá sentido ao mundo.

A ideia de rede de sentidos remete a uma configuração profunda porque assume uma perspectiva "encarnada" do nosso modo de produzir significação. Ela não afeta meramente nossa intelecção, mas nossa sensibilidade e nosso modo de habitar o mundo. Como tal, ela frequentemente "trai" nossos discursos aparentemente mais coerentes e convencionais. Pensar a partir da rede de sentidos, portanto, é pensar a partir de uma “infraestrutura" que não é facilmente dominável. Foi nesse sentido, por exemplo, que tentei refletir recentemente (2015b) sobre algumas raízes da vida política brasileira a partir das nossas históricas e complexas relações raciais.

Um aspecto complementar e fundamental é o desenvolvimento do conceito de antagonismo, construído a partir da obra de Ernesto Laclau e Chantal Mouffe (2015). Ele parte da perspectiva relativamente comum de que grupos sociais em convivência não compartilham, em alguns aspectos essenciais, a mesma rede de sentidos. Considerando-se que a hierarquia de valores que cada uma deles compreende é vivida de modo profundamente "incorporado" por cada grupo, a tendência é que essa dissonância provoque algum grau de inaceitação mútua. Os contatos de grupos nessas condições podem provocar diversas naturezas de negociações, 
que dependem em grande parte dos mecanismos de poder utilizados por cada um. De um modo geral, entretanto, sempre haverá diversas naturezas de troca decorrentes desse contato, sendo que os limites extremos, possivelmente apenas parcialmente alcançados, são uma completa relação de dominação de um grupo e submissão do outro. Mesmo que esses limites nunca sejam efetivados de forma pura, as relações costumam ser assimétricas; assim, as "trocas" de sentido envolvidas costumam carregar em si algum grau de dominação e submissão.

É a partir desses fundamentos filosóficos que tentarei pensar, a princípio, a ideia de Ocidente. As noções correlatas de rede de sentidos e antagonismo não serão evocadas a cada momento, mas devem servir de pano de fundo para toda a investigação. Será fundamental, por exemplo, para a compreensão das ideias de Ocidente e modernidade, perceber os signos que essas noções evocam, e o jogo valorativo que está associado a esses signos. Será fundamental perceber, também, que as significações produzidas possuem uma temporalidade que lhes é inerente, temporalidade que também se dá de modo valorativo. É essa produção valorativa de sentidos, que nunca é neutra, que dará sustentação e justificação às diversas práticas que concernem à modernidade e à colonialidade.

\section{OCIDENTE, MODERNIDADE, COLONIALIDADE}

Se os signos podem ser mais bem compreendidos a partir das relações a ele associadas, a ideia de Ocidente pode estar vinculada a diversos outros signos. Fernando 
Coronil (1996), por exemplo, a vincula a centro e primeiro mundo, em contraposição a Oriente, periferia e terceiro mundo, numa evidente associação valorativa mais próxima da contemporaneidade. Huntington (1993, p. 13) associa o Ocidente a "individualismo, liberalismo, constitucionalismo, direitos humanos, equidade, liberdade, o poder da lei, democracia, livres mercados, a separação entre Igreja e Estado". Serge Latouche, por sua vez, faz uma interessante afirmação:

O Ocidente tem a ver com uma entidade geográfica, a Europa, com uma religião, a cristandade, com uma filosofia, o Iluminismo, com uma raça, a raça branca, com um sistema econômico, o capitalismo, e (...) no entanto não se identifica com nenhum desses fenômenos. (1994, p. 34).

Por fim, neste primeiro levantamento, vale citar o livro Formations of modernity, organizado por Stuart Hall e Bram Gieben (1992), cujo tema central, tal como seu título denuncia, é a ideia de modernidade. Depois de vários capítulos que descrevem a conformação dessa ideia, falando de temáticas como iluminismo, formação do Estado moderno, a emergência da economia, a transformação de estruturas sociais de classe e gênero e a formação da sociedade moderna, o próprio Stuart Hall finaliza o livro utilizando-se do termo West (que podemos traduzir como Ocidente), com um capítulo de título provocante: "The West and the rest" (o Ocidente e o resto). Neste capítulo, ele associa plenamente o conceito de Ocidente com o de modernidade. 
Por 'Ocidente' queremos significar o tipo de sociedade discutida nesta série: desenvolvida, industrializada, urbanizada, capitalista, secular e moderna. Tais sociedades emergiram em um período histórico particular - mais ou menos durante o século XVI, depois da Idade Média e do rompimento do feudalismo. (HALL, 1992, p. 276-277).

Aqui, temos alguns elementos importantes de investigação: ao associar tão completamente "Ocidente" a "modernidade", já não faz tanto sentido identificar o Ocidente, como normalmente estamos acostumados, à Idade Média cristã, ao Império Romano, muito menos ao mundo grego clássico. Rejeitar essa associação imediata não significa, naturalmente, rejeitar que a modernidade ocidental tenha sido influenciada por estas perspectivas, apenas recusar esta identificação imediata. Dussel, por exemplo, ao discutir a formação da ideia de "Europa" (durante muito tempo quase um sinônimo de "Ocidente") afirma que "a diacronia unilinear Grécia-RomaEuropa é um invento ideológico do século XVIII romântico alemão" (DUSSEL, 2000, p. 24) . Ele lembra que a Europa medieval, em sua maior parte, não estava diretamente vinculada à experiência grega, aliás bem menos do que os intelectuais bizantinos e islâmicos. A queda de Constantinopla pelos turcos dá à Europa ocidental certa primazia da cristandade, e coloca os turcos, "orientais", como o inimigo a ser enfrentado.

No renascimento italiano (especialmente depois da queda de Constantinopla em 1453), começa uma fusão nova: o ocidental latino se une com o grego oriental e enfrenta o mundo turco, que esquecendo a origem helenística- 
bizantina do mundo muçulmano, permite a seguinte equação falsa: ocidental = helenístico + romano + cristão. Nasce assim a 'ideologia' eurocêntrica do romantismo alemão (DUSSEL, 2000, p. 26).

Partindo desta constatação, assumimos com Stuart Hall que há certa aproximação fundamental entre as ideias de Ocidente e modernidade. No entanto, elas produzem sentidos diferentes. Sem dúvida, a narrativa da modernidade foi estabelecida no solo europeu (no "Ocidente"), mas ela remete acima de tudo a uma narrativa temporal, não espacial. Falar em modernidade significa falar de um determinado momento do processo histórico em que se deram grandes transformações. Digamos, sem ser exaustivo: expansão marítima e mercantilismo, revolução protestante, invenção da imprensa, revolução científica, filosofia política baseada no indivíduo e na propriedade, elevação do sujeito humano à base do conhecimento (e consequente relação sujeito-objeto), pensamento iluminista, ideia de progresso, revoluções democráticas, separação entre igreja e Estado. E, claro, o capitalismo. Mais recentemente, falar em modernidade significa contrapor um período histórico que, a depender do intérprete, já supera valores essenciais da própria modernidade ou os exacerba. É nesse sentido que se fala em pós-modernidade ou hipermodernidade.

Se a narrativa da modernidade é mais temporal do que espacial, ela frequentemente carrega em si uma experiência de inevitabilidade. O signo que se contrapõe mais diretamente ao de modernidade é o de pré-modernidade. A modernidade, nesse sentido, significa uma transformação inevitável de 
modos de vida "tradicionais", como foi acontecendo na Europa, especialmente a partir do século XVI. Claro que os povos "modernos" confrontam-se com diversos povos "pré-modernos", e que alguns deles nem sequer alcançarão necessariamente a modernização, mas é possível se pensar nesses povos como se eles estivessem num tempo diferente, visto que o tempo hegemônico e inexorável é o da modernidade.

É interessante, nesse sentido, o papel ideológico do conceito de progresso, só desenvolvido plenamente como tal ao final do século XVIII. Segundo Koselleck, este conceito, uma vez amadurecido, torna-se um "singular coletivo que aglutina numerosas experiências em uma expressão" (2012, p. 106). Esta noção vai conformando uma aparentemente inédita percepção de irreversibilidade do tempo histórico, em contraposição a tempos cíclicos e tempos "biológicos" (nascimento, amadurecimento, decadência e morte) frequentemente pensados por outras experiências.

A opinião de que o progresso é geral e contínuo enquanto que qualquer retrocesso, decadência ou degeneração apenas tem lugar de forma parcial e passageira constitui uma ideia típica do século XVIII, amplamente estendida desde então. [..] Esta mudança se comprova em muitos autores: Turgot, Condorcet, Iselin, Wieland ou Kant, para mencionar alguns, ou já no século XIX, Engels, Haeckel ou Eduard Von Hartmann (KOSELLECK, 2012, p. 104).

Possivelmente, a materialização mais dramática dessa ideia de progresso se dê na "evolução dialética" pensada por 
Hegel. Nela, é fundamental a condição inexorável da evolução da história, para além de indivíduos e povos específicos. Para Hegel, "A história universal é o progresso na consciência da liberdade - um progresso cuja necessidade temos de reconhecer" (2008, p. 25). No contexto da evolução inevitável da história da humanidade e da "astúcia da razão" que nela é promovida, o destino dos povos depende totalmente de sua participação nessa história. É nesse sentido que o Oriente asiático teve um papel de "parir" o espírito do mundo, mas também que há possíveis povos do futuro (como os homens brancos da América do Norte) e outros que são simplesmente irrelevantes. Por exemplo, pouco depois de afirmar que "o verdadeiro palco da história universal é a zona temperada" (2008, p. 84), Hegel diz: "apesar de termos algumas informações sobre a América e sua cultura, principalmente sobre o México [Astecas e Maias] e o Peru [Incas], sabemos que foram povos bem primitivos, que fatalmente sucumbiriam assim que $o$ espírito se aproximasse deles" (2008, p. 85).

Enfim: a ideia de modernidade, ao carregar em seu signo essa noção de inevitabilidade temporal, tende a silenciar o seu "outro", aquele que "naturalmente" irá ser superado diante do avanço do espírito. Mesmo noções de "fim da modernidade", "pós-modernidade" ou "hipermodernidade", não à toa antecedidas por ideias de "decadência do Ocidente", não deixam de participar desse tempo histórico. Mesmo que já rompendo com a linha ascendente da ideia iluminista de progresso, a referência dessas narrativas continua a ser ocidental, quase sem nomear o Ocidente, exceto retoricamente (muito menos os modos não ocidentais). Podemos dizer que narrativas da "modernidade" e da "pós-modernidade" têm poder idêntico de negar outras narrativas. 
Diferente dessa noção tão associada à temporalidade, signos como "Europa" e "Ocidente" já apresentam conotações diferentes. Sua natureza mais espacial, embora de uma espacialidade sempre móvel, convida a pensar o que está além das suas fronteiras. Não é por acaso, nesse sentido, que Stuart Hall sinta necessidade em falar em "West and the rest", mas que os demais capítulos do seu livro não tenham tido a mesma preocupação ao abordar diretamente a modernidade. Assim, algumas noções do início da modernidade que irão gestar a ideia atual de Ocidente, como "Europa" e "cristandade", foram sendo conformadas em contraposição e enfrentamento dos seus contrários. Iver Neumann, por exemplo, mostra como a ideia de "Oriente" (East) foi fundamental para a formação da identidade europeia, desde os muçulmanos e chegando mesmo à Rússia da Guerra Fria (NEUMANN, 1998). Como já afirmado anteriormente, Dussel mostra a importância da contraposição do europeu ao mundo otomano, e lembra que as "cruzadas são a primeira tentativa da Europa latina de impor-se no Mediterrâneo oriental. Fracassam, e com isso a Europa latina segue sendo uma cultura periférica, secundária e ilhada pelo mundo turco e muçulmano" (2000, p. 24).

Mas certamente, foram as explorações europeias a partir do século XV, capitaneadas por Portugal e Espanha, que conformaram outra natureza profunda de definição do Ocidente e da modernidade. Como afirma Hall (1992), a exploração portuguesa na costa da África (a partir de 1430) e as viagens de Colombo para a América foram marcos de um novo padrão de exploração. Este processo pode marcar a passagem da era "medieval" para a era "moderna", com forte expansão do comércio e do mercado e a emergência de 
monarquias centralizadas na França, Inglaterra e Espanha. Tudo associado a aumento de produtividade, crescimento da população e desenvolvimento das artes e da ciência. Cada vez mais a Europa "superava" a Ásia.

Estes signos são associados: modernidade como uma temporalidade inexorável e evolutiva; Ocidente/Europa como a emergência espacial de uma civilização "superior", o "palco" da modernidade, em contraposição a povos "primitivos", "bárbaros" ou "tradicionais". A sua utilização distinta, neste aspecto, dependerá do sentido que se queira adotar. Juntos, eles narram determinado modo de simbolização de um processo histórico que podemos localizar a partir do final do século XV; se quisermos, podemos considerar 1492 uma data simbólica da sua emergência ${ }^{5}$.

Normalmente associamos a modernidade a uma emergência significativa do homem como fonte central da autoridade e da agência. É esta noção que faz dele, a partir de então e especialmente de Descartes, o "subiectum", o que subjaz, contraponto à ideia moderna de objeto, estabelecendo a nova relação sujeito-objeto. Segundo Heidegger ,"a objetividade originária é o 'eu penso', no sentido do 'eu percebo (...). Na ordem da gênese transcendental do objeto, o sujeito é o primeiro objeto da re-presentação ontológica" (2006, p. 64). Aníbal Quijano também vincula, como Heidegger, a formação da modernidade com a relação sujeito-objeto, sendo Descartes o seu principal avatar. Afirma Quijano:

Com Descartes, o que sucede é a mutação da antiga abordagem dualista sobre o "corpo" e o "não-corpo". $\mathrm{O}$ que era uma presença permanente de ambos os 
elementos em cada etapa do ser humano, em Descartes se converte numa radical separação entre "razão/sujeito" e "corpo". A razão não é somente uma secularização da ideia de "alma" no sentido teológico, mas uma mudança, uma nova id-entidade, a "razão-sujeito", a única entidade capaz de conhecimento "racional", em relação à qual o "corpo" é e não pode ser outra coisa além de "objeto" de conhecimento (QUIJANO, 2005, p. 129).

Porém, é fundamental para ele associar a constituição dessa relação com o processo de colonização. Como Dussel afirma: "O ego cogito moderno foi antecedido em mais de um século pelo ego conquiro (eu conquisto) prático do hispano-lusitano, que impôs sua vontade (...) ao índio americano" (2000, p. 29). Sob essa perspectiva, a construção teórica de Descartes foi antecedida pela construção prática do homem europeu, pela experiência efetiva, que materializa o surgimento de um tipo mais avassalador de conquista.

Nesta mesma perspectiva, Santiago Castro-Gómez diz que o que Habermas chamou de "projeto da modernidade" deve ser pensado como "a tentativa fáustica de submeter a vida inteira ao controle absoluto do homem, sob o guia seguro do conhecimento" (CASTRO-GÓMES, 2000, p. 88). E acrescenta que desde Francis Bacon a natureza é pensada como "o grande 'adversário' do homem, como o inimigo que se deve vencer para domesticar as contingências da vida e estabelecer o regnum hominis sobre a terra" (Ibid., p 88). Nesta perspectiva, podemos falar da relação sujeito-objeto como uma relação que concede ao homem uma centralidade aparentemente inédita, a partir da qual todo o seu entorno torna-se objeto de ação e 
conhecimento. O que lhe resiste, em última instância ${ }^{6}$, como a própria "natureza", deve ser domado, controlado.

É sob o signo dessa relação sujeito-objeto que a modernidade constitui uma noção inédita de indivíduo. De um modo geral, ela se antepõe a perspectivas holísticas que subordinavam o homem a algum elemento de autoridade anterior: o kósmos, a polis, Deus ou o rei, por exemplo. Esta noção vai sendo constituída em diversos planos do pensamento e da sensibilidade ocidental. Ela aparece no Cogito individual cartesiano, mas também em toda teoria do conhecimento constituída a partir daí, chegando ao sujeito transcendental kantiano e mesmo à fenomenologia husserliana; ela é fundamental para teorias políticas contratualistas e/ou liberais desenvolvidas na modernidade (Hobbes, Locke, Kant, Stuart Mill e mesmo Rawls, na contemporaneidade). Mas ela também povoa a literatura, especialmente dos séculos XVIII e XIX, com personagens de vidas individuais "empreendedoras" e capazes de se realizar sem ajuda de mais ninguém, como talvez o modelo mais exemplar seja o de Robinson Crusoé (MORETTI, 2014) ${ }^{7}$.

O indivíduo assim pensado forja um mundo particular que independe, supostamente, do meio que o envolve. Ele pressupõe sujeitos já conformados previamente, antes mesmo da formação de uma sociedade política. O homem descrito pelas narrativas originais da modernidade não é, de modo inerente, um animal político, como pensava Aristóteles, mas um ser livre e em grande medida atomizado que, a posteriori, percebe a necessidade de constituição de uma sociedade política para lidar com os "inconvenientes" das relações entre os indivíduos. Estes delineamentos proporcionam dois 
lados paradoxais, mas complementares, do que chamarei de paradoxo da modernidade.

De um lado, há certa narrativa positiva do ideário liberal, que alimentou boa parte dos discursos políticos e ideológicos que lhe deram sustentação. Segundo essa narrativa, compõe a formação do sujeito liberal/moderno/ocidental um indivíduo igual aos outros em direitos, livre, empreendedor e normalmente competitivo. Este indivíduo tem uma vida privada que deve ser protegida e, como corolário de sua ação empreendedora, propriedades que é capaz de adquirir progressivamente. Se pensarmos a leitura kantiana do direito à propriedade, teremos clareza da profunda correlação dessa noção com a prévia e moderna relação sujeito-objeto, assim como o pressuposto de domínio da natureza que essa relação enseja. Como afirma Kersting, segundo a concepção de Kant, "o ser humano é o senhor do mundo; o mundo como a totalidade das coisas utilizáveis não humanas está à sua disposição" (KERSTING, 2012, p. 349). É nesse sentido que a sua posse se constitui para Kant "um direito à propriedade de qualquer objeto do mundo externo e, assim, possuir a autoridade de excluir qualquer outro do uso deste objeto" (Ibid., p. 348).

Assim, o homem moderno, livre e igual, com sua privacidade e suas propriedades protegidas, é capaz de competir livremente e, assim fazendo, contribuir para a riqueza de sua comunidade, aspecto reforçado pela ideia de livre comércio que esta perspectiva enseja (SMITH, 1996a e $1996 \mathrm{~b})^{8}$. Somados esses componentes, temos alguns valores essenciais cultivados pela modernidade: igualdade (formal), liberdade individual, direito à propriedade, privacidade, livre 
comércio. Em última instância, são valores positivos. A ideia liberal de liberdade negativa (BERLIN, 2009) corresponde à necessidade moderna de proteger esses valores da coerção de outros seres humanos.

Mas há outro lado da modernidade ocidental a ser considerado. Normalmente, esses valores positivos ocultam, ao menos parcialmente, outro conjunto de valores que quase necessariamente lhes são correlatos. Como já dito, a ascensão do sujeito humano, na modernidade, pressupõe, como sua contraparte inerente, certo domínio sobre o objeto e, mais especificamente, sobre a natureza. Mais do que uma perspectiva meramente teórica, este foi um elemento prático essencial que permitiu a manutenção, no campo simbólico, de certo sujeito "desencarnado". O mundo moderno, cada vez mais "civilizado" e complexo, exigia um aparato de domínio sobre a natureza que, partindo de Rodolfo Kusch, podemos materializar no conforto das cidades, que parcialmente nos protege e conjura certos medos essenciais da ira da natureza. Para Kusch, na cidade "o medo do mundo foi substituído pela criação de outro mundo"; nesse contexto,

o que havia ficado de fora da muralha era o mal, ou seja, essa mesma porção que se obteve dentro da cidade como bem. Lá ficava o que era referente ao corpo, ao diabo, enquanto aqui se dava o espírito. Assim se faz a muralha espiritual que, ao fim e ao cabo, não é mais que a defesa frente à ira (KUSCH, 1999, p. 105).

Assim, esse mundo espiritual percebido por Kusch exige, necessariamente, um processo de exclusão. Mas Kusch não aprofundou que o que é excluído corresponde quase sempre ao 
que é capaz de transformar a natureza e propiciar o mundo "espiritual": o indígena colonizado, o escravo africano, o proletário europeu, a mulher - mesmo a mulher europeia, a que cuida da casa e dos filhos. Assim, se a modernidade foi constituída pela relação sujeito-objeto, elevando o "homem" (termo já em si ambíguo) à condição de sujeito explorador da natureza, foi igualmente fundamental para a sua constituição certa mobilidade do que deve ser considerado como sujeito e do que deve ser considerado como objeto-natureza; excluído, portanto, da categoria essencial de sujeito, ou ao menos não detentor da condição de sujeito (político ou do conhecimento) de pleno direito.

O campo político é emblema fundamental para este processo constante de exclusão. $O$ modelo liberal não considerava incluir os servos e trabalhadores ("não proprietários") no seu contrato social; do mesmo modo, não considerava incorporar as mulheres. Quanto aos povos colonizados, ainda menos. É emblemático pensar que, ao falar no "estado de natureza", em que havia o suficiente para todos, Locke venha a dizer que "a terra inteira era a América" (LOCKE, 2001). A América representaria, neste caso, uma terra pré-política em que ainda não valia o modelo político proposto.

Nesta contraposição se instaura um dos aspectos centrais do paradoxo da modernidade. A "igualdade" moderna sempre foi prenhe de diversos modos de desigualdade. Naturalmente, a história da humanidade sempre foi uma história de diferenciações (bárbaros e gregos ou bárbaros e romanos, por exemplo), mas o ideário moderno de igualdade produzia novos paradoxos, tentativas cada vez mais ambíguas 
de incluir-excluir. E a relação homem-natureza teve um papel essencial nessa ambiguidade. Anne McClintock, por exemplo, mostra como havia uma mescla no imaginário da América que aglutinava colonizados, natureza e feminilidade. Isso se traduzia da forma mais violenta com certa "licença" dos conquistadores para roubar, estuprar. Nesse contexto, "a feminilização da terra é ao mesmo tempo uma poética da ambivalência e uma política da violência" (McCLINTOCK, 1995, p. 28). É parte dessa ambiguidade a ânsia de nomear, batizar como sua a terra a ser conquistada, dominá-la. É no mesmo sentido que as terras são "descobertas", como numa redescoberta chancelada pelo homem branco.

O mito da terra virgem é também o mito da terra vazia, envolvendo uma desapropriação de gênero e de raça. Nas narrativas patriarcais, ser virgem é ser vazio de desejo, de ação sexual, passivamente esperando o empuxo, a inseminação masculina da história, da linguagem e da razão (...).De acordo com esse tropos, as pessoas colonizadas - como as mulheres e a classe trabalhadora nas metrópoles não habitam propriamente a história, mas existem em um tempo permanentemente anterior no espaço geográfico do império moderno como humanos anacrônicos, atávicos, irracionais, desprovidos de agência humana - incorporação viva do 'primitivo' arcaico (McCLINTOCK, 1995, p. 30). ${ }^{9}$

Assim, o "homem" sujeito da modernidade nunca representou, na prática, o conjunto da humanidade. A inclusão do humano sempre se fez pari passu, paradoxalmente, com 
diversos mecanismos de exclusão. Para além de sujeitos específicos, estes mecanismos sempre representaram, ao mesmo tempo, modos particulares de estar no mundo. $\mathrm{O}$ sujeito moderno-ocidental deve ser conformado de um determinado modo e só a partir dessa conformação pode ser considerado como tal. O seu corpo e seus costumes deveriam ser forjados para que ele se tornasse "civilizado". Em seu clássico O processo civilizador, Norbert Elias afirma que o conceito de civilização

expressa a consciência que o Ocidente tem de si mesmo. [..] Ele resume tudo em que a sociedade ocidental dos últimos dois ou três séculos se julga superior a sociedades mais antigas ou a sociedades contemporâneas 'mais primitivas'. Com essa palavra, a sociedade ocidental procura descrever o que lhe constitui o caráter especial e aquilo de que se orgulha: nível de sua tecnologia, a natureza de suas maneiras, o desenvolvimento de sua cultura científica ou visão de mundo, e muito mais (ELIAS, 1994, p. 23).

Este aspecto é fundamental para se compreender que o sujeito moderno ocidental foi sendo forjado na modernidade. Ele não representa uma "cultura" ocidental em abstrato. Em grande medida, os povos europeus também foram submetidos a mecanismos rigorosos de adestramento para que fossem conformados como tal. E este adestramento os colocava, cada vez mais, em contraponto à natureza, como sujeitos desprendidos livres e racionais, como um self pontual e sustentado por uma visão atomística da sociedade (TAYLOR, 
2000, p. 19). Ou seja: a exclusão não é apenas de determinados "sujeitos", mas também de determinados modos de vida, especialmente para aqueles que efetivamente representarão a modernidade. Estes precisam ser depurados para serem, de fato, sujeitos de pleno direito.

O paradoxo da modernidade propiciou diversos modos de reação. $O$ processo de ocidentalização/modernização nunca se fez em abstrato e pacificamente. Ele sempre lidou com pessoas de carne e osso de diversas culturas e com diversos modos de apreensão da realidade. De um lado, ele se materializou nas diversas e complexas etapas de implementação do capitalismo no globo, o que significou progressivamente conquista de mercados globais, domínio da natureza, mercantilização de diversos aspectos da vida, enfraquecimento de culturais locais, fortalecimento dos Estados e burocratização, incremento tecnológico, entre outros aspectos. De outro lado, o antagonismo que estes processos ensejam serviu de base para diversas reações, mesmo que muitas deles sejam readaptadas posteriormente pelo próprio sistema modernidade/ocidentalização/capitalismo. Estas reações incluíram, para citar algumas delas, lutas democráticas a partir do final do século XVIII ${ }^{10}$, movimentos feministas, lutas por direitos indígenas e por direitos civis dos negros, movimentos anticoloniais, movimentos ecológicos e pacifistas, entre outros.

No campo da filosofia, diversos modos de pensamento contestaram alguns dos pressupostos originais de construção da modernidade, a partir de teorias marxistas, hermenêuticas, pósmodernas ou pós-estruturalistas, feministas, anticolonialistas ou descolonialistas, entre outras. Como o processo descrito 216 
é extremamente complexo e poderoso, naturalmente muitas dessas teorias puderam ser parcial ou totalmente assimiladas.

\section{A FILOSOFIA NA AMÉRICA LATINA E 0 OCIDENTE}

Postos os aspectos anteriores, gostaria agora de situar a filosofia na América Latina, diante da questão do Ocidente como problema filosófico. Para fazer isso, sinto necessidade de colocar, preliminarmente, uma questão mais básica: o que fazemos mesmo quando fazemos filosofia?

Antes de tudo, é importante constatarmos isso: fazemos algo, a filosofia é, como todo exercício disciplinar, uma prática. Como tal, o reconhecimento da sua atividade se dá antes de tudo pelo modo como a exercemos. A reflexão teórica sobre a natureza dessa prática já corresponde a uma espécie de filosofia da filosofia e assim lida com a imprecisão típica dos conceitos filosóficos. Não é à toa, portanto, que os filósofos divirjam tanto sobre a própria natureza do filosofar.

Pensar filosoficamente a filosofia pode ter dois objetivos diferentes, e não é fácil discerni-los. Um deles é criar um "critério de demarcação" que permita dizer o que é e o que não é filosofia - num desdobramento desse objetivo, o que é e o que não é uma filosofia rigorosa. Julio Cabrera $(2003,2013)$ chama atenção há tempos quanto ao risco desse empreendimento. $\mathrm{O}$ conceito delimitado de filosofia se tornaria uma espécie de salvo-contudo para os fiscais da "verdadeira filosofia" - e essa é sempre a nossa, naturalmente, em detrimento da "outra" filosofia. ${ }^{11}$ Penso que esta pertinente preocupação não nos deve eximir do exercício de pensar a nossa atividade. Mas deve 
nos tornar mais vigilantes quanto à natureza desse exercício e quanto à abertura e imprecisão de toda aventura filosófica. Nesse sentido, pensar filosoficamente o exercício filosófico não deve implicar jamais em arrogar-se a possibilidade (e a pertinência) de se formular um conceito acabado, definitivo, que almeje excluir outras possibilidades.

Feita esta ressalva, eu vejo um segundo e mais interessante objetivo. Ao pensarmos filosoficamente a atividade filosófica, tratamos a própria filosofia como um conceito. Ao fazermos isso, damos à nossa reflexão a potência possível dos conceitos, possibilitamos "um processo de instauração do sentido", como afirmou Fréderic Cossutta (2001, p. 41) sobre a atividade filosófica em geral. Na minha perspectiva, e por experiência pessoal, a compreensão melhor acabada deste processo, antes de nos restringir, nos liberta. Se damos um sentido potente à atividade filosófica, temos a possibilidade de criar novas formas a partir deste sentido e não meramente repetirmos formas importadas. É nesse contexto que proponho avançarmos.

Deleuze e Guattari assim definiram a filosofia:

A filosofia, mais rigorosamente, é a disciplina que consiste em criar conceitos [..]. Criar conceitos sempre novos é o objeto da filosofia [..]. Os conceitos não nos esperam inteiramente feitos, como corpos celestes. Não há céu para os conceitos. Eles devem ser inventados, fabricados ou antes criados, e não seriam nada sem a assinatura daqueles que os criam (DELEUZE e GUATARRI, 1992, p. 13).

Por outro lado, Fréderic Cossutta pensa a filosofia como "reexame e redefinição do conceito" (2001, p. 40). Mas se 
aproxima de Deleuze e Guattari ao completar que "embora sejam os constituintes elementares da reflexão, os conceitos não são dados como se preexistissem à própria filosofia, mas são construídos, e esta elaboração constitui uma parte determinante da atividade filosófica" (Ibid., p.40). Ou seja: em ambas as definições, o conceito aparece como o "objeto" por excelência da filosofia, e ambas rejeitam visões (talvez platônicas ou correlatas) que pensariam que os conceitos devem ser "descobertos" - antes, eles são criados, forjados, construídos. Mas a ênfase de Deleuze e Guattari em "conceitos sempre novos" é diferente da perspectiva de Cossutta. Este parece atribuir uma tarefa mais comezinha ao filósofo, já que lhe cabe reexaminar ou redefinir conceitos, com o prefixo de ambos os verbos remetendo à possível tarefa reflexiva da filosofia, uma tarefa que também permite lidar com "materiais" já desenvolvidos por outros.

Eu mesmo tentei fazer uma síntese própria sobre filosofia, há alguns anos atrás:

o processo de reflexão sobre conceitos ou sistemas de conceitos em torno de fundamentos (mesmo que de forma pós-moderna, para questionar esses fundamentos) ou questões últimas do humano, desenvolvidos por meio de processos argumentativos, mais que imagéticos e fabulares, sendo palco constante de processos de incorporação e refutações (SOMBRA, 2012, p. 17).

De algum modo, resgato nessa definição uma noção recusada por Deleuze e Guattari, mas não por Cossutta (a ideia de reflexão), acrescento as disputas internas da atividade 
filosófica (incorporações e refutações) e abordo dois aspectos adicionais que, no próprio artigo, já reconheço como frágeis: a questão dos fundamentos (cada vez mais recusada; embora eu defenda que recusar fundamentos já é lidar filosoficamente com eles) e a forma imagética e fabular. Em relação a esta última, de Platão a Nietzsche, a filosofia nunca deixou de produzir imagens e fábulas, mas também nunca deixou de rejeitar essa forma como seu recurso primordial.

Mas há algo em comum a todas essas definições, todas elas abordando a mesma prática de modos diferentes? Por que o conceito é a sua matéria? Penso que o que diferencia a filosofia de outras atividades parte da constatação de que o seu exercício não corresponde a uma descrição de fatos/acontecimentos/ discursos. O tempo todo, fazemos arte, religião, ciência, agimos moralmente, assumimos posturas estéticas, fazemos política ou nos omitimos dela, damos e ouvimos/lemos explicações religiosas, cosmológicas, científicas ou mitológicas sobre o mundo. Num nível mais abstrato, escrevemos "tratados teóricos" sobre cada uma dessas atividades, numa tentativa de "segunda ordem" de abordá-las. É claro que essa abordagem teórica já exige, em diversos momentos, a utilização de conceitos. Mas a filosofia remete a um processo que podemos chamar de "terceira ordem", de tentativa de compreensão da rede de sentidos dessas atividades e dessas descrições teóricas ou, mais radicalmente, de reformulação delas ${ }^{12}$.

Esta descrição filosófica a remete quase necessariamente a uma semântica imprecisa, a conceitos fugidios (como o próprio conceito de filosofia!) que não são explícitos, de imediato, nas atividades e mesmo nas descrições de segunda ordem. Essa semântica imprecisa tem de ser argumentada. O filósofo tem de convencer a sua pretensa audiência de que 
o que ele propõe é razoável, que permite-nos contemplar ou reformular as atividades (primeira ordem) ou os tratados teóricos (segunda ordem) aos quais os conceitos formulados se referem de modo mais apodítico, irrecusável, verdadeiro, preciso, instigante, renovador, crítico - os adjetivos já compõem uma longa cadeia histórica e podem mudar com o tempo. Em diversos momentos, os filósofos tentaram estabelecer que tipo de argumento é válido e/ou rigoroso e que tipo não é. Há verdadeiros tratados sobre isso, mas é preciso ter a humildade de admitir que os modos de argumentação são tão diferentes quantos os filósofos.

Cada vez mais se desconfia de que o resultado de uma teoria filosófica seja "verdadeiro", no sentido de que exclui qualquer outra possibilidade alternativa de formulação como "falsa". Certamente se cobra alguma coerência interna, e os adjetivos acima sugeridos são estabelecidos como critérios possíveis de uma boa teoria. Quando entramos em contato com uma descrição filosófica que nos parece valiosa, isso acontece porque ela pode ter um impacto relevante sobre o nosso olhar e a nossa percepção acerca das nossas atividades de primeira e de segunda ordem. Na maior parte das vezes, essas atividades desempenhadas não são envolvidas em um grau máximo de reflexão e/ou percepção crítica. Pensar o significado profundo de alguns dos aspectos que as envolvem pode produzir um efeito importante de repensar o significado delas, até de colocá-las em xeque; de, eventualmente, transformarmos a nossa própria sensibilidade a partir desse novo significado.

Nesse sentido, pensar filosoficamente pode ser uma atitude praticamente política. Essa atitude pode remeter a uma confirmação de tudo o que está sendo construído ou 
a uma redescrição que permita que pensemos criticamente sobre isso. Sempre que estivermos sobre certo regime de "pensamento único", essa redescrição poderá ser fundamental. Vale acrescentar que essas fronteiras não são rígidas. De um modo menos discursivo, as grandes obras de arte costumam transformar alguns aspectos fundamentais da nossa rede de sentidos. ${ }^{13}$ As teorias científicas, principalmente em momentos fundamentais, também o fazem. ${ }^{14}$ Talvez o que caracterize a filosofia é a atividade discursiva de se voltar especificamente para esse objetivo, ter o conceito como a sua matéria por excelência.

Mas, naturalmente, a formulação filosófica não surge do nada. Se Aristóteles pensava que ela partia de um espanto [thaumazein], mesmo que não concordemos que este seja o afeto universal da filosofia, aqui é interessante sinalizar que há um afeto que a move, ou seja, literalmente somos afetados por algo e queremos dialogar com este afeto a partir de uma nova proposição conceitual, a partir de um reexame ou uma redefinição que nos permita lidar melhor com aquilo que sempre fizemos ou transformá-lo. Concretamente, falando, uma filosofia não se realiza sem um problema que a impulsione a se realizar. Segundo Deleuze e Guattari, "todo conceito remete a um problema, a problemas sem os quais não teria sentido, e que só podem ser isolados ou compreendidos na medida de sua solução" (1992, p. 27-28). E acrescentaram:

Dizemos de qualquer conceito que ele sempre tem uma história, embora a história se desdobre em ziguezague, embora cruze talvez outros problemas ou outros planos diferentes. Num conceito, há, no mais das vezes, 
pedaços ou componentes vindos de outros conceitos, que respondiam a outros problemas e supunham outros planos. (1992, p. 29-30).

Partindo dessa perspectiva, devemos pensar que o filosofar sempre estará vinculado a esse ato (e esse afeto, poderíamos acrescentar) mais originário: um problema que será investigado e, talvez, parcialmente resolvido com o desenvolvimento e/ou reexame de novos conceitos filosóficos. Não podemos excluir dessa atividade o que costumamos chamar de "comentadores", os pensadores que investigam de forma exegética a formulação filosófica de outros pensadores. Frequentemente, esta atividade traz novas iluminações ao conceito previamente elaborado, novas nuances são descobertas, novas possibilidades são reveladas. Entretanto, se há uma vinculação profunda entre o conceito e o seu problema, a própria exegese deveria reexaminar o problema anteriormente levantado ou pensar o conceito a partir de problemas estabelecidos pelo próprio exegeta, o que não deixa de significar a produção de uma nova filosofia.

E é neste momento que nos deparamos com nossa questão original, pensar a filosofia na América Latina tendo a questão do Ocidente como um problema. De um lado, certamente somos atravessados por diversas questões tipicamente "ocidentais". Vivemos no sistema capitalista e, mais recentemente, numa "ordem neoliberal"15; nosso sistema político e de direitos, nosso modo hegemônico de fazer ciência (e filosofia), nosso modo hegemônico de produção artística, parte significativa da nossa religiosidade, todos esses aspectos têm forte influência ocidental. Por outro lado, somos atravessados 
por formas não ocidentais de cultura, especialmente negra e indígena, e este amálgama também transforma, de modo diferente para grupos sociais diferentes, nosso modo de estar no mundo, nossa religiosidade, e mesmo nossa relação com o trabalho e a atividade econômica. Implica, também, em uma relação diferenciada com as atividades econômicas típicas do capitalismo e (ainda) em uma profunda divisão racial no país, apesar da nossa mestiçagem ${ }^{16}$. A própria relação prática com a ideia de indivíduo pode ser transformada. ${ }^{17}$

O que isso significa para a formulação dos nossos problemas filosóficos? Não teríamos algo de diferente a refletir em relação a certos valores fundamentais à constituição moderna, como relação sujeito-objeto, individualismo, propriedade, colonização, capitalismo? Não podemos pensar outro sistema de direitos e outro modo de conceber a política? Não haverá outra gramática para o que pensamos ou não ser ético? O nosso modo de produzir conhecimento e de apreensão estética não é transformado pela nossa condição? Nossa religiosidade e nosso modo mesmo de enfrentá-la não será outro? Não somos eventualmente afetados por outra metafísica?

Seguindo Julio Cabrera, questionar estes aspectos não nos remete a uma questão "nacional". Não se trata aqui de uma "filosofia brasileira ou latino-americana", nem sequer de problemas "tipicamente" brasileiros ou latino-americanos, mas de uma perspectiva que seja situada.

os pensamentos filosóficos nascem dentro de redes holísticas de proposições, crenças, propostas, valores vigentes etc. e ganham certa configuração [..] dentro 
delas, configuração essa que é produzida por uma perspectiva e por uma circunstância; dependendo da procedência do pensamento, predomina uma configuração ou outra (CABRERA, 2015, p. 8).

Com alguma proximidade conceitual, isto significa dizer: os pensamentos filosóficos (também) nascem a partir da sua própria rede de sentidos, eles não formulam "visões de lugar nenhum". Se a filosofia concerne a modos discursivos de tentativas de instauração de sentido ou a partir do reexame e da reformulação da "gramática profunda" (para usar uma imagem de Wittgenstein) das nossas atividades, me parece razoável pensar que esta gramática é transformada, ao menos parcialmente, em cada situação. Mesmo que parcialmente ela se utilize de diversos signos e componentes que atravessem povos e gerações.

Se pensarmos nesta difícil questão em torno da filosofia, comparando-a com uma "atividade de segunda ordem" pensemos na sociologia, como exemplo - , teremos maior dimensão da natureza do nosso problema. Um sociólogo brasileiro pode, por exemplo, fazer uma pesquisa acerca das transformações sociais no centro antigo de Salvador-Bahia. Ele pode, por sua vez, se utilizar para tanto de metodologias de sociólogos europeus ou norte-americanos. Haveria, nesse caso, uma ambiguidade. Uma discussão "descolonizadora" no campo da sociologia poderia reivindicar "metodologias do sul" para tais abordagens, ou mais especificamente metodologias latino-americanas. Mesmo nesse caso, porém, o sociólogo apresentou uma preocupação com questões locais. Se outros pesquisadores quiserem pesquisar o centro antigo, quase 
incontornavelmente deverão se voltar para a sua pesquisa. Num sentido mais concreto, dificilmente uma reflexão sobre o Brasil irá abdicar de intelectuais como Gilberto Freyre, Sérgio Buarque de Holanda, Florestan Fernandes, Caio Prado Junior, Celso Furtado, entre outros. Outra discussão, e que não nos cabe aqui, é o quanto eles se utilizaram de metodologias (e, ainda mais profundamente, fundamentos filosóficos) de autores "importados" para os seus empreendimentos e o quanto forjaram fundamentos "locais" para tanto.

No caso da filosofia, estas questões ganham outro grau de problematização. Se a "gramática profunda" que perpassa a filosofia pode discutir conceitos tão amplos quanto identidade, diferença, liberdade, poder, sujeito, igualdade, ética, linguagem, significação, corpo, mente, mundo, substância, matéria, tempo, espaço, natureza, cultura, entre outros, todos esses signos parecem remeter a uma "universalidade" que mais facilmente independe de uma situação. A própria história das pesquisas filosóficas que atravessam épocas e regiões parece dar razão a essa "visão de lugar nenhum".

Parecemos aceitar com mais facilidade que esses pequenos "fundamentos" do pensamento sejam formulados e conceituados por uma tradição de autores europeus/norteamericanos e quase sempre nos contentamos em burilar e rediscutir essas formulações. Mas, para usarmos a imagem de Anne McClintock anteriormente citada, não nos submetemos pacificamente às suas nomeações? Se os conceitos filosóficos correspondem a um modo discursivo de definir/reformular alguns dos elementos essenciais da nossa rede de sentidos, o que significa assumirmos que praticamente todos eles sejam chancelados pela intelectualidade ocidental hegemônica? Se, 
como afirmou Cabrera, os pensamentos filosóficos nascem de "dentro de redes holísticas de proposições, crenças, propostas, valores vigentes etc.", onde ficaram as nossas próprias "redes holísticas" na formulação dos nossos pensamentos filosóficos? A formulação sempre a partir do universo europeu e norteamericano não tende a nos remeter a estranhas, embora muito bem elaboradas, "ideias fora de lugar"18? Por que somos tão pouco sensibilizados por outras estéticas, éticas e metafísicas? E quando o fazemos (raramente), por que isso parece muitas vezes um mero exercício estilístico e não fundamentado em problemas realmente vividos?

Mas há outro aspecto a ser considero, aqui. Nos questionamentos elaborados acima, foi comum o pronome "nós" e as conjugações dele decorrentes. Mas quem somos "nós"? "Nós", os latino-americanos? (nós, os brasileiros?). Esta nomeação não é demasiado equívoca? Se o processo de "ocidentalização" se deu também por meio de diversos mecanismos de exclusão (de pessoas e de atributos das pessoas), certamente em uma faixa importante da população este processo minou boa parte do antagonismo e da reação possível. Neste sentido, se "Ocidente" não chega a ser uma realidade plausível, ao menos as "ideias fora de lugar" de Ocidente parecem nos seduzir. Em filosofia, isso representa quase sempre a nossa reverência quase impensada a conceitos e valores ocidentais.

Mas, sem dúvida, há algo "fora de lugar" mesmo nelas. No mínimo, se nos atemos ao permanente jogo de inclusãoexclusão que nos cabe na América Latina (em relação ao "Ocidente"), ao profundo fosso que nos atravessa e que frequentemente nos coloca (digamos) entre a favela e o 
condomínio (DUNKER, 2015), a tendência é que cheguemos à conclusão de que não compartilhamos a mesma temporalidade ocidental. Não temos o mesmo passado e também somos atravessados por outras tradições. A perspectiva de futuro que nos move remete a outras aberturas e (im)possibilidades.

Pensar uma perspectiva situada significa nos posicionarmos diante do modo específico com o qual somos afetados pelo paradoxo da modernidade na América Latina. E sabemos que não somos afetados do mesmo modo, quer sejamos ricos ou pobres; negros, brancos ou indígenas; homens ou mulheres; homossexuais ou heterossexuais; ateus, cristãos ou de uma religião de matriz africana; bolivianos, argentinos ou brasileiros; nortistas ou sulistas (no caso do Brasil). Como estas condições também não nos determinam, somos afetados de modos diferentes pelo modo com que recebemos e interpretamos estes condicionamentos, pelo modo particular com que estas questões (e outras) afetam a nossa vontade de fazer (ou ler) filosofia.

Isso implicará diversas possibilidades de se fazer filosofia ou, mesmo que a obra não seja propriamente filosófica em sua proposta, de se construir novas gramáticas. Possivelmente, em todos os casos isso acontecerá em diálogo com conceitos ocidentais, mesmo quando se escreve a partir de bases não ocidentais. Quando Rodolfo Kusch pensa sua América profunda a partir da cultura pré-colombiana, a diferença entre ser e estar se estabelece em diálogo com a noção ocidental de ser (KUSCH, 1999). Quando Viveiros de Castro (1996) formula a noção de um "perspectivismo ameríndio" e, nela, redimensiona possibilidades de se lidar com noções como natureza e cultura, e até mesmo homem e animal, ele também dialoga com conceituações ocidentais, 
para fazer isso. Em ambos os casos, de todo modo, há uma delimitação clara em função de um diálogo com povos e possibilidades ostensivamente não ocidentais. Estes cruzamentos, entretanto, também são válidos quando as possibilidades são mais híbridas (BHABHA, 1998), quando, estranhamente, somos e não somos ocidentais, e o que somos se dá de um modo particular que tem de ser reapropriado. Segundo Dussel,

De modo diferente dos africanos e asiáticos (...) a maioria da população latino-americana (...) não é (...) nem ameríndia nem europeia. (...) É em torno do mestiço que vai sendo construída o que se chama 'América Latina' (...) como bloco cultural. O mestiço viverá em seu corpo e sangue a contraditória figura da Modernidade (DUSSEL, 1993, p. 165-166)

Isso tudo já deveria merecer outras possibilidades filosóficas, outros conceitos e, neles, outros modos de vida possíveis.

\section{NOSSA PRÁTICA, ENFIM}

A formação das nossas academias parece reforçar nossa dificuldade. Nós somos inseridos, com algum grau de disciplina e rigor, na tradição dos conceitos filosóficos ocidentais, mesmo quando remetem a uma "tradição" recente no caso da filosofia contemporânea. Aqueles que são bem sucedidos tornamse capazes, em seus artigos, livros, dissertações e teses, de elaborarem leituras inteligentes do que foi desenvolvido por autores clássicos gregos e latinos, ou por autores franceses, 
alemães, ingleses e norte-americanos (talvez italianos e espanhóis) na modernidade e na contemporaneidade. Em alguns casos, estas leituras chegam a fazer alguma articulação com problemáticas mais imediatamente locais.

Mas o que resulta está longe de ser suficiente. Tentemos imaginar a atividade filosófica como uma grande teia de produção, leitura, análise, comentário e crítica de textos filosóficos. Essa grande teia acontece desde a formação de novos alunos (graduandos e mestrandos, por exemplo), passa por pesquisadores já formados no âmbito da filosofia e se segue por leitores fora do universo profissional da filosofia desde profissionais de outras áreas, que se valem de conceitos filosóficos, até leitores diletantes. Não é relativamente consensual que há uma baixa vitalidade nessa teia, quando os textos produzidos partem de autores latino-americanos? A "produção original" (criação de conceitos, novas instaurações de sentido) não tem priorizado fortemente filósofos europeus/ norte-americanos? Mesmo quando os autores latinoamericanos são lidos, as produções preferenciais remetem a seus "comentários" (análises, discussões, problematizações) de conceitos desenvolvidos por autores europeus. ${ }^{19}$ Os nossos eventuais trabalhos autorais não têm provocado grande interesse para a maioria dos pesquisadores de outras áreas, e mesmo de leitores diletantes. Complementarmente, alguns poucos filósofos de destaque parecem almejar muito mais uma aceitação ou "reconhecimento" em escala global que ensejar uma nova vitalidade à teia local.

Se esta fraca vitalidade é real, ela pode ter motivações que não são excludentes; ao contrário, muito provavelmente elas são complementares. De um lado, criamos uma "cultura" 
interna que não se interessa por autores latino-americanos. Desenvolvemos um fascínio (performativamente reforçado) pelos autores europeus e norte-americanos, de modo que "dividi-los" com autores "locais" significaria uma perda de prestígio. As nossas pesquisas, assim, não serão muito incentivadas para investigar obras filosóficas de Farias Brito, Carlos Vaz Ferreira, Vicente Ferreira da Silva, Evaldo Coutinho, Oswald de Andrade, Paulo Freire ${ }^{20}$, Enrique Dusssel, Leopoldo Zea, Rodolfo Kusch, Juan Carlos Scannone ou Julio Cabrera. De outro lado, damos pouca oportunidade para a criação filosófica e para o desenvolvimento dos nossos próprios problemas. Os cursos de graduação não costumam dar esse incentivo ou desenvolver disciplinas especificamente "criativas". Para além deles, a baixa receptividade das obras autorais locais já tende a significar, antecipadamente, um desincentivo ou um desestímulo à sua produção, eventualmente tratada como uma tentativa "exótica" de formulação por um diletante ainda despreparado.

Com essa rede performativa de desestímulo à formulação filosófica local, produzimos um curioso cenário. A nossa produção (cada vez mais profissionalizada, como sinaliza Julio Cabrera (2013)) ganha um papel secundário de refinadora da semântica da produção europeia/norte-americana. Se o Ocidente é na verdade um processo de "ocidentalização", tendemos a absorver quase acriticamente este processo. Quando somos críticos a ele, tendemos a nos utilizar de uma gramática também europeia, como críticas marxistas, hermenêuticas, neopragmatistas ou pós-estruturalistas quem sabe a linguagem pós-colonialista de matriz inglesa, ou os cultural studies. 
Sinalizar para estes fatores não significa propor o inverso, abdicarmos do diálogo com a filosofia europeia/norte-americana em nome de uma suposta filosofia latino-americana. Significa reivindicar um exercício político-formador que nos convide a pensar nossos próprios problemas, e arriscarmos nossa própria gramática, mesmo que em diálogo com conceitos e formulações de outras plagas. Não sabemos com clareza sequer quem é o "nosso" desta frase, mas uma perspectiva mais situada certamente nos convidará a diversificar as possibilidades gramaticais. Certamente, continuaremos a dialogar com grandes pensadores ocidentais ao fazer isso. Mas, num espírito antropofágico, eles deverão ser "digeridos" de acordo com nossas próprias questões, assim como podem ser digeridos autores africanos e asiáticos, por exemplo. Não é possível se antecipar o que resulta de tal inversão, mas também não é difícil pensar que à medida que intensifiquemos nossas redes locais e sejamos capazes de produzir, discutir, refutar e reformular as nossas próprias obras, uma nova vitalidade possa emergir a partir daí. Com ela, a tendência de que nos identifiquemos cada vez mais com nossa própria gramática. E que nossa sensibilidade filosófica seja cada vez menos "fora de lugar".

\section{NOTAS}

${ }^{1}$ Professor Adjunto de Filosofia da Universidade Estadual de Feira de Santana (UEFS). Doutor em Filosofia pela Universidade Federal da Bahia (UFBA). E-mail: lausombra@hotmail.com.

${ }^{2}$ Informações obtidas no link http://www.amnation.com/vfr/archives/005372. $h t m l$, acessado em 09/12/2016, às 10:30.

${ }^{3} \mathrm{O}$ que isto significa, em última instância, será discutido em seguida. 
4 Dussel já havia desenvolvido essa questão em seu livro 1492: o encobrimento do outro (1993).

${ }^{5}$ Esta associação não é trivial ou incomum. Ela já foi feita por diversas vezes, como em Dussel (1993), Todorov (2003), Attali (1992), entre tantos outros. O grupo "modernidade/colonialidade", anteriormente citado, vincula diretamente a modernidade ao processo de conquista da América.

"É interessante que um termo frequentemente usado para "objeto" (ou "matéria", "assunto"...) em alemão é Gegenstand. E gegen remete diretamente à ideia de oposição, como diversas vezes lembrado por Heidegger e Gadamer. Gadamer, por exemplo, sugere que o conceito de Gegenstand representa "aquilo que executa uma resistência, o que resiste à imposição natural e à inserção nos acontecimentos da vida" (2006, p. 111). O objeto, então, é arrancado pelo sujeito a partir de uma resistência, não é mero objeto de contemplação como se dava na theoria aristotélica.

${ }^{7}$ Certamente podemos incluir na formação dessa sensibilidade o herói solitário (quase sempre homem, registre-se) do cinema norte-americano, como o cowboy, o guerreiro (como o Rambo de Stallone, por exemplo) ou o policial/detetive. Eventualmente desajustados, eles têm, entretanto, a capacidade isolada de salvar um mundo ou um povo. Mesmo que eventualmente precisem, para tanto, deixar um rastro de sangue em mexicanos, indígenas, russos, asiáticos ou árabes (os “outros" da vez).

${ }^{8}$ Como afirmam Dardot e Laval (2016), a partir de Herbert Spencer, começa a ser forjado um novo tipo de liberalismo (que derivaria no neoliberalismo do século XX) que já não garante o "benefício de todos". A ideia de concorrência ganha, aqui, uma noção forte de "sobrevivência dos mais aptos", numa adaptação intraespécie da obra de Darwin.

${ }^{9}$ Se é que é preciso reforçar a posição de McClintock, basta ler um trecho do filósofo espanhol do século XVI Juan Ginés de Sepúlveda, defensor da "guerra justa contra os índios", em oposição ao frei dominicano Bartolomé de las Casas: "sendo (...) coisa justa por direito natural que a matéria obedeça à forma, o corpo à alma, o apetite à razão, os brutos ao homem, a mulher ao marido, o imperfeito ao perfeito, o pior ao melhor, para o bem de todos (...)" (Apud DUSSEL, 1993, p. 75).

${ }^{10}$ Em trabalho anterior (SOMBRA, 2015c), tentei fazer um histórico conceitual 
das lutas democráticas desde a Revolução Francesa, mostrando como elas se contrapunham fortemente aos interesses liberais, num primeiro momento. No entanto, especialmente a partir do século XX, elas foram perdendo o seu poder contestador, sendo frequentemente incorporadas ao amálgama das "democracias liberais" ocidentais. Mesmo esse esvaziamento, contudo, foi ainda considerado perigoso pelos movimentos neoliberais especialmente a partir da década de 70, o que paradoxalmente serve de base para renovadas lutas democráticas a partir de então.

${ }^{11}$ Além das suas publicações, tive ao menos uma conversa pessoal com Julio Cabrera sobre essa sua preocupação. Agradeço-lhe por me chamar a atenção para um aspecto que eu considerava pouco até aquele momento.

${ }^{12}$ Nesse sentido, a proposta de reflexão e reexame que eu e Cossutta apresentamos pode ser insuficiente em relação à "criação" de Deleuze e Guattari. A filosofia, naturalmente, não apenas "reflete" mundos e modos de vida, mas também pode criá-los e recriá-los. Ou, no mínimo, formular conceitos que permitam que eles sejam vistos e vividos de um modo inédito. Na prática da atividade filosófica, entretanto, estas fronteiras não são rígidas, e talvez seja prudente deixar todas elas como possibilidades, alternativas ou complementares, do exercício filosófico.

${ }^{13}$ É nesse sentido que compreendo a visão de Julio Cabrera (2007) de que o cinema produz "conceitos logopáticos" (carregados de afeto e de sensibilidade), sendo que esta também pode ser uma possibilidade da filosofia. De um modo geral, as obras de arte em geral têm essa propriedade, sendo que as maiores delas podem transformar a nossa rede de sentidos, "abrir um mundo" como afirmava Heidegger em A origem da obra de arte (2002).

${ }^{14}$ Baseados em Thomas Kuhn, podemos pensar que, nas ciências, os momentos de transição de um paradigma em crise para um novo sejam momentos especialmente filosóficos. Como afirma Kuhn, por exemplo, "a transição da mecânica newtoniana para a quântica evocou muitos debates a respeito da natureza e dos padrões da física" (2005, p. 73). Possivelmente, estas questões são ainda mais complexas nas ciências humanas, já que elas costumam comportar, em suas fileiras, diversas "linhas teóricas" divergentes, que exigem reflexões filosóficas ainda mais frequentes para sua fundamentação.

${ }^{15}$ Pierre Dardot e Christian Laval mostram, por exemplo, que mais que uma doutrina econômica, estamos sob a égide de uma racionalidade neoliberal, que "tem como característica principal a generalização da 
concorrência como norma de conduta e da empresa como modelo de subjetivação" (2016, p. 17). Mais adiante eles exemplificam, com algo que nos é caro no âmbito da pesquisa universitária. "Pense-se em particular na generalização dos métodos de avaliação no ensino público oriundos da empresa" (Ibid., p. 26). Casos particulares de estudos da repercussão da perspectiva neoliberal (em sentido amplo) na Universidade têm sido pesquisados; um exemplo foi a pesquisa recentes de três geógrafas em uma Universidade norte-americana, com o valor adicional de inserir esta pesquisa a partir de diferenciações étnicas e de gênero (HAWKINS et al, 2014).

${ }^{16}$ Tentei aprofundar essa reflexão (SOMBRA, 2015b). Naturalmente, há diversos estudos mais aprofundados sobre essa matéria, com diferentes perspectivas.

${ }^{17}$ Certamente, o próprio capitalismo, e sua exacerbação no neoliberalismo, nos convida performativamente a um reforço da noção de indivíduo, com noções fortes de concorrência, empregabilidade, capital humano etc. Mas há diversos contrapontos parciais a esse modo em países com culturas não totalmente ocidentais. Como exemplo, Charles Taylor (1997, p. 60-62) nos apresenta a diferença na formação de jovens norteamericanos em Connecticut, que são estimulados a deixar a casa paterna para desenvolverem sua conversão individual, em relação a jovens indianos, estimulados a permanecer profundamente vinculados à sua família ampliada. Podemos citar, também, a recusa política de indígenas bolivianos em encampar modos "ocidentais" de decisões políticas individuais, de modo profundamente diferente das tomadas de decisão tradicionais (Linera, 2008). No Brasil, além de experiências de povos indígens, quilombolas e de fundo de pasto, certamente a sociabilidade nas favelas brasileiras diverge, ao menos parcialmente, das formas tipicamente ocidentais.

${ }^{18}$ Em artigo já mencionado (SOMBRA, 2015b), tentei ampliar aspectos do conceito de Roberto Schwartz na investigação da realidade brasileira.

${ }^{19}$ A partir do site academia.edu, tenho acompanhado a recepção de meus artigos. Sem dúvida, aqueles que falam de Heidegger e Wittgenstein, por exemplo, são bem mais procurados que os mais "autorais".

${ }^{20}$ Oswald de Andrade e Paulo Freire são bastante pesquisados no Brasil, respectivamente no campo da literatura e da educação, mas pouco como filósofos. 


\section{REFERÊNCIAS}

ARDILES, Osvaldo Et al. Hacia una filosofia de la liberación latinoamericana. Buenos Aires: Ed. Bonum, 1973.

ATTALI, Jacques. 1492: os acontecimentos que marcaram o início da era moderna. Tradução Denise Rangé Barreto. Rio de Janeiro: Nova Fronteira, 1992.

BERLIN, Isaiah. "Dois conceitos de liberdade: o romântico e o liberal". In: BERLIN, Isaiah. Ideias politicas na era romântica: ascensão e influência no pensamento moderno. Tradução Rosaura Eichenberg. São Paulo: Companhia das Letras, 2009.

BHABHA, Homi. O local da cultura. Tradução Myriam Ávila (et al). Belo Horizonte: Ed. UFMG, 1998.

CABRERA, Julio. Margens das filosofias da linguagem: conflitos e aproximações entre analíticas, hermenêuticas, fenomenologias e metacríticas da linguagem. Brasília: Ed. da Unb, 2003.

CABRERA, Julio. De Hitchcock a Greenaway pela história da filosofia: novas reflexões sobre cinema e filosofia. São Paulo: Nankin, 2007.

CABRERA, Julio. Diário de um filósofo no Brasil. 2a Edição. Ijuí: Ed. Unijuí, 2013.

CABRERA, Julio. "Europeu não significa universal, brasileiro não significa nacional (acerca da expressão 'filosofar-desde'). Revista Nabuco, 2, Janeiro de 2015. 
CASTRO-GÓMEZ, Santiago. "Ciencias sociales, violencia epistémica y el problema de la 'invención del otro"'. In: LANDER, Edgardo (Comp.). La colonialidade del saber: eurocentrismo y ciencias sociales. Perspectivas latinoamericanas. Buenos Aires: CLACSO Ed, 2000.

CASTRO-GÓMEZ, Santiago y GROSFOGUEL, Ramón (comp.). El giro decolonial: reflexiones para una diversidad espistémica más allá del capitalismo global. Bogotá: Siglo del Hombre Editores, 2007.

CORONIL, Fernando. "Beyond Occidentalism: toward nonimperial Geohistorical categories". Cultural Anthropology, Vol 11, 1 (Feb 1996), pp. 51-87.

COSSUTTA, Fréderic. Elementos para a leitura dos textos filosóficos. $2^{\text {a }}$ Edição. Tradução Angela de Noronha Begnami (et al). São Paulo: Martins Fontes, 2001.

DARDOT, Pierre e LAVAL, Crhistian. A nova razão do mundo: ensaio sobre a sociedade neoliberal. São Paulo: Boitempo, 2016.

DELEUZE, Gilles e GUATTARI, Félix. O queéa filosofia?Tradução Bento Prado Jr. e Alberto Alonso Muñoz. Rio de Janeiro: Ed. 34, 1992.

DUNKER, Crhistian Ingo Lenz. Mal-estar, sofrimento e sintoma: uma psicopatologia do Brasil entre muros. São Paulo: Boitempo, 2015.

DUSSEL, Enrique. 1492: o encobrimento do outro. A origem do mito da modernidade. Petrópolis-RJ: Vozes, 1993. 
DUSSEL, Enrique. "Europa, modernidad y eurocentrismo". In: LANDER, Edgardo (Comp.). La colonialidade del saber: eurocentrismo y ciencias sociales. Perspectivas latinoamericanas. Buenos Aires: CLACSO Ed, 2000.

ELIAS, Norbert. O processo civilizador. Volume 1: uma história dos costumes. $2^{\text {a }}$ Ed. Tradução Ruy Jungman. Rio de Janeiro: Jorge Zahar Ed., 1994.

GADAMER, Hans-Georg. O caráter oculto da saúde. Tradução Antônio Luz Costa. Petrópolis-RJ: Vozes, 2006.

HALL, Stuart and GIEBEN, Bram (Ed.). Formations of modernity. Cambridge: Polity Press, 1992.

HALL, Stuart. "The West and the rest: discourse and power". In: HALL, Stuart and GIEBEN, Bram (Ed.). Formations of modernity. Cambridge: Polity Press, 1992.

HAWKINS, Roberta, MANZI, Maya and OJEDA, Diana. "Lives in the making: power, academia and the everyday". ACME, 2014, 13 (2), 238-351.

HEGEL, Georg Wilhelm Friedrich. Filosofia da história. $2^{\text {a }}$ Edição. Tradução Maria Rodrigues e Hans Harden. Brasília: Ed. da Unb, 2008.

HEIDEGGER, Martin. "A origem da obra de arte". In: HEIDEGGER, Martin. Caminhos de floresta. Lisboa: Fundação Calouste Gulbenkian, 2002. 
HEIDEGGER, Martin. "A superação da metafísica". In: Ensaios e Conferências. 3a. Ed. Tradução Márcia Sá Cavalcante Schubak. Petrópolis: Vozes, 2006.

HEIDEGGER, Martin. Ser e Tempo. 4a Ed. Tradução Márcia Sá Cavalcante Schuback. Petrópolis: Vozes, 2009.

HUNTINGTON, Samuel. “The Clash of civilizations?”. Foreign Affairs, vol. 72 (Summer 1993), pp. 22-49.

KERSTING, Wolfgang. "Politics, freedom, and order: Kant's political". In: GUYER, Paul (Ed.) The Cambridge Companion to Kant. Cambridge: Cambridge University Press, 2012.

KOSELLECK, Reinhart. Historias de conceptos: estudios sobre semántica y pragmática del lenguage político y social. Madrid: Editorial Trotta, 2012.

KUHN, Thomas. A estrutura das revoluções cientificas. $9^{a}$ Edição. Tradução Beatriz Vianna Boeira e Nelson Boeira. São Paulo: Ed. Perspectiva, 2005.

KUSCH, Rodolfo. América profunda. Buenos Aires: Biblos, 1999.

LACLAU, Ernesto e MOUFFE, Chantal. Hegemonia e estratégia socialista: por uma política democrática radical. Tradução Joanildo Burity, Josias de Paula Jr. e Aécio São Paulo: Intermeios, 2015. 
LANDER, Edgardo (Comp.). La colonialidade del saber: eurocentrismo y ciencias sociales. Perspectivas latinoamericanas. Buenos Aires: CLACSO Ed, 2000.

LATOUCHE, Serge. A ocidentalização do mundo: ensaio sobre a significação, o alcance e os limites da uniformização planetária. Tradução Celso Mauro Paciornick. Petrópolis-RJ: Vozes, 1994.

LINERA, Álvaro Garcia. A potência plebeia: ação coletiva e identidades indígenas, operárias e populares na Bolívia. Tradução Mouzar Beneditino e Igor Ojeda. São Paulo: Boitempo, 2010.

LOCKE, John. Dois tratados sobre o governo. Traduzido por Julio Fischer. São Paulo: Martins Fontes, 2001.

McCLINTOCK, Anne. Imperial leather: race, gender and sexuality in the colonial contest. New York, Routledge, 1995.

MORETTI, Nani. O burguês: entre a história e a literatura. Tradução Alexandre Morales. São Paulo: Três Estrelas, 2014.

NEUMANN, Iver B. Uses of the other: 'the East' in European identity formation. Minneapolis: University of Minnesota Press, 1998.

QUIJANO, Aníbal. "Colonialidad y moderniad-racionalidad”. In: BONILLA, Heráclito (compilador). Los conquistados: 1492 e la población indígena de las Américas. Bogotá, Tercer Mundo Editores, 1992. 
SAUSSURE, Ferdinand de. Curso de Linguística Geral. 28a Edição. Tradução Antônio Chelini et al. São Paulo: Ed. Cultrix, 2012.

SMITH, Adam. A riqueza das nações: investigação sobre sua natureza e suas causas. Volume 1. Tradução Luiz João Baraúna. São Paulo: Ed. Nova Cultural, 1996a.

SMITH, Adam. A riqueza das nações: investigação sobre sua natureza e suas causas. Volume 2. Tradução Luiz João Baraúna. São Paulo: Ed. Nova Cultural, 1996b.

SOMBRA, Laurenio Leite. "Filosofia: de que se trata?". Revista Pandora, 40, Março de 2012, p. 14-21.

SOMBRA, Laurenio Leite. "Identidade dos sujeitos: linguagem, constituição de sentido e valor". Revista Sísifo, n. 1, v. 1, 2015a.

SOMBRA, Laurenio Leite. "Escândalo da Política Brasileira: o sentido da desigualdade". In: Revista Ideação, n. 32, jul./dez/ 2015b. pp. 59-99.

SOMBRA, Laurenio Leite. "Democracy in the presence of liberalism”. In: GALUPPO, Marcelo Et al (Editors). Human rights, rule of Law and the contemporary social challenges in complex societies: proceedings of the XXVI World Congress of Philosophy of Law and Social Philosophy of the Internationale Vereinigunf für Rechts - und Socialphilosophie. Belo Horizonte: Initia Via Editora, 2015c.

TAYLOR, Charles. As fontes do self: a construção da identidade moderna. Tradução Adail Ubirajara Sobral e Dinah de Abreu Azevedo. São Paulo: Ed. Loyola, 1997. 
TAYLOR, Charles. Argumentos filosóficos. Tradução Adail Ubirajara Sobral. São Paulo: Ed. Loyola, 2000.

TODOROV, Tzvetan. A conquista da América: a questão do outro. $3^{\text {a }}$ Ed. Tradução Beatriz Perrone-Moisés. São Paulo: Martins Fontes, 2003.

VIVEIROS DE CASTRO, Eduardo. “Os pronomes cosmológicos e o perspectivismo ameríndio”. Mana, 2 (2): 115-144, 1996.

WITTGENSTEIN, Ludwig. Investigações Filosóficas. 4a Edição. Tradução Marcos Montagnoli. Petrópolis: Vozes, 2005. 